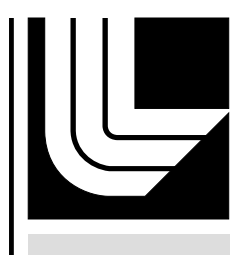

LAW RENCE LIVERMORE N A TIO N A L LABORATORY

2004 Annual Health Physics

Report for the HEU

Transparency Program

R. Radev

May 3, 2005 
This document was prepared as an account of work sponsored by an agency of the United States Government. Neither the United States Government nor the University of California nor any of their employees, makes any warranty, express or implied, or assumes any legal liability or responsibility for the accuracy, completeness, or usefulness of any information, apparatus, product, or process disclosed, or represents that its use would not infringe privately owned rights. Reference herein to any specific commercial product, process, or service by trade name, trademark, manufacturer, or otherwise, does not necessarily constitute or imply its endorsement, recommendation, or favoring by the United States Government or the University of California. The views and opinions of authors expressed herein do not necessarily state or reflect those of the United States Government or the University of California, and shall not be used for advertising or product endorsement purposes.

This work was performed under the auspices of the U.S. Department of Energy by University of California, Lawrence Livermore National Laboratory under Contract W-7405-Eng-48. 
UCRL-TR-211924

\title{
2004 Annual Health Physics Report for HEU Transparency Program
}

\author{
Radoslav Radev \\ Lawrence Livermore National Laboratory
}

During the 2004 calendar year, LLNL provided health physics support for the Highly Enriched Uranium Transparency Implementation Program (HEU-TIP) in external and internal radiation protection and technical expertise into matters related to BDMS radioactive sources and Russian radiation safety regulatory compliance. For the calendar year 2004, there were 200 person-trips that required dose monitoring of the U.S. monitors. Of the 200 person-trips, 183 person-trips were SMVs and 17 person-trips were Transparency Monitoring Office (TMO) trips. Eight person-trips from the SMV trips were continuation trips of TMO monitors to facilities other than UEIP. The LLNL Safety Laboratories' Division provided the dosimetry services for the HEU-TIP monitors.

\section{External Dosimetry}

LLNL provided 864 TLD dosimeters in 2004 for monitoring for potential external dose: 376 personal dosimeters, 308 control dosimeters and 180 spares to UEIP and Western Services in Moscow. Approximately 522 of the dosimeters supplied were returned as "not worn". The "not worn" number includes the unused spare dosimeters from UEIP and Moscow and both the personal and control arbitration TLDs left in Russia until a post trip dose letter is provided. The current agreements require only one set of two U.S. TLDs for each monitor visiting any of the Russian plants. An additional 96 dosimeters were used for an ongoing study of the impact of the airport x-ray security screening on the TLD recorded dose.

In 2004, all HEU-TIP monitors went on assignments in Russia with a complete set of personal and control dosimeters. In order to avoid a failure of a trip mission due to lost dosimeters at customs, a pool of 60 spare dosimeters is maintained at Western Services in Moscow, in addition to the 30 spare TLDs at the TMO. The spare dosimeters are exchanged semi-annually. Customs letters for both the U.S. and Russian customs were included in the dosimeters packages for each trip to facilitate customs inspections if needed. LLNL retrieved all 2004 arbitration dosimeters from the monitored Russian nuclear facilities.

In 2004 LLNL provided DOE's HEU-TIP management with post trip dose reports after each trip. All HEU monitors received zero doses from external radiation exposure in 2004. Based on our studies of the x-ray exposure during flight and during luggage screening at airports, the reliable lower limit of external dose (TLD) determination beginning in calendar year 2005 will be set to 20 mrem. Evaluation of the new limit according to the DOE Standard for Performance Testing of Personnel Dosimetry Systems $\mathrm{DOE} / \mathrm{EH}-0027$ is provided in Appendix A. The procedure will significantly reduce the time and the effort spent in extended dose investigations. From January 2005 any TLD readings below 20 mrem will be recorded as a zero dose. 


\section{External dose investigations}

There were 24 external dose investigations of measured individual doses by the TLDs (MPA - 1; UEIP - 2; ECP - 8; SChE - 13). These results in question were very close to the 2004 recordable limit (10 mrem) and were caused by radiation type or levels very unlikely to be encountered in the visited facilities or caused by issues associated with the control TLDs. Furthermore, the information about the activities, area visited and time spent by the monitors does not support significant occupational exposures. The investigations in all cases determined that the TLD readings were not associated with occupational exposure; rather they were likely caused by multiple exposures at airport luggage x-ray screenings. The accumulated personal dose history, the arbitration TLDs, and the radiological data from the plants were very helpful for resolving the exposure investigations.

\section{Exposures from screening luggage at airports}

LLNL conducted studies of the effect of airport security x-ray screening of the checked-in and hand-carried luggage. Our tests indicate that checked-in luggage on international and domestic flights is exposed, on average, to 20-80 mrem (and in some cases on non-HEU foreign travel, to over $200 \mathrm{mrem}$ ). Our tests indicate that not all airports (domestic and international) have installed or use new x-ray units with increased exposure levels. The average dose data from the $\mathrm{X}$-ray screening of checked-in luggage from trips to Ekaterinburg, Seversk, Tomsk, Washington D.C., and New York (JFK) is provided in Appendix B. On the other hand, the hand-carried luggage on international and domestic flights is exposed on average to 1-8 mrem. A detailed discussion on the impact of these exposures was provided to HEU management in a November 11, 2003 memo. To minimize the effects of airport $x$-ray screening on the evaluated personal doses, our procedures require that the TLDs be transported in a hand-carried luggage.

No other external dose and radiation safety concerns were raised during the 2004 calendar year.

\section{Internal Dosimetry}

A total of 182 bioassay samples were submitted in 2004: 173 post-trip (for uranium) and 9 baseline samples (for uranium and plutonium). There are no outstanding bioassay samples from 2004 to be submitted in 2005. All HEU-TIP monitors who participated in assignments in Russian uranium processing facilities have provided baseline bioassay samples. Currently, all bioassay samples from monitoring assignments in 2004 have been analyzed and the results are entered in the HEU-TIP Health Physics database. All analyzed bioassay samples in 2004 calendar year showed results that were below or at the normal background level with the exception of one sample that was insignificantly above that level, which necessitated investigation. The bioassay result evaluation determined that no occupational intake and internal dose could be associated with that result. No other internal dose and corresponding radiation safety concerns were raised during 2004 year. The internal dose is assigned based on the bioassay result (content of uranium compounds in urine), appropriate biokinetic models, chemical and physical form of uranium compounds and other pertinent information. The minimum detectable internal dose (MDD) from uranium bioassays depends on several factors, two of which are the 
chemical and physical form of the uranium compound and the time elapsed between a potential uranium intake and the time the bioassay sample was provided. Appendix C provides values of MDD for various uranium compounds and times of providing the bioassay sample. The information underscores the importance of providing a bioassay sample as soon as possible and of adhering to the safety precautions.

In 2004, LLNL introduced a new shipping procedure for bioassay samples that minimized the consequences of a bioassay sample spill and that is in compliance with the DOT regulations. LLNL provided DOE's HEU-TIP management with quarterly internal dose reports (bioassay reports) containing information on the internal dose, the baseline bioassays, the procedure compliance and the status of bioassay samples received, analyzed and in process of being analyzed. The established bioassay procedure requires each monitor to provide a post trip bioassay sample within 3 days of arrival in the United States. For 2004 calendar year, $93 \%$ of the samples were in compliance with this requirement, with the average time interval between the arrival of the monitors in the United States and the providing of the post trip bioassay sample being 1.6 days. Only three monitors have provided bioassay sample more than 10 days after their return to the United States. Appendix D of this report has a chart providing information on the bioassay sample compliance for 2004 calendar year.

\section{HEU health physics information database}

LLNL maintains a confidential database for the HEU radiation protection data. The database contains historical external and internal dose information for every HEU-TIP monitor, as well as specific information for each trip, TLDs supplied, returned or left in Russia, baseline bioassays, and monitor's data. The health physics database is essential for generating the post trip and the annual dose reports. The HEU health physics database was improved in 2004 to better meet the needs of HEU-TIP radiation protection activities. This work will continue in 2005. In order to comply with the provisions of the Privacy Act of 1984, we have obtained and filed signed Radiation Exposure Release forms for all HEU-TIP monitors that had assignments in the calendar 2004. This information is also kept in the health physics database and is updated as new monitors are added to the active monitors list. The individual annual occupational dose information for each monitor for 2004, detailing the total dose as well as the external and internal doses from each monitoring assignment, was mailed to each monitor in the first quarter of 2005 .

\section{Radiological data from the Russian plants}

The 2004 radiological data, received from the Russian uranium processing plants under the HEU agreement, do not indicate that there are radiological concerns for the U.S. monitors working in Russia who follow the work and personnel protection guidelines. The attached graphs in Appendix E (Appendix E is a separate C/FIG-MOD document) provide the gamma exposure levels, airborne and surface contamination in the monitoring points for each of the plants in 2004. The guiding action levels are provided at the left of 
the graphs. Some surface contamination values for the Seversk Chemical Enterprise (SChE) conversion plant exceed the "low dose level" (no U.S. concern level) which provides further emphasis to the requirement that monitors use personal protective equipment (lab coats, gloves, etc.) and avoid touching Russian equipment. Detailed plant radiological data along with the action levels and the recommended precautions were included in the dosimetry package for each SMV and TMO trip in 2004.

\section{Health physics support of the BDMS activities}

During CY 2004 LLNL provided support in the dose rate measurements around the Blend Down Monitoring Systems (BDMSs) for Russian regulatory compliance, in the development of procedures for the californium sources relative measurements, and assisted in preparing the BDMS source specifications. LLNL also provided neutron dosimetry support to the Ural Electrochemical Integrated Plant (UEIP), Russian Federal Nuclear Center - Institute of Technical Physics (VNIITF, C-70), ElectroChemical Plant, Zelenogorsk (ECP) and SChE, negotiated "relaxed" radiation dose rates limits at SChE and UEIP and assisted in the development and shipment of new equipment in support of the californium sources relative measurements.

\section{Neutron and gamma dose rate measurements for regulatory compliance}

In 2004 the quality of the dose rate measurements for regulatory compliance was significantly improved at all sites. A consistent measurement methodology was agreed on with our Russian plants counterparts and implemented. This methodology improves the accuracy and allows a better comparison of measurement results from different years and different sources. The improved quality and accuracy of the measurement results provide additional confidence in the source characteristics and their proper installation and manipulation. During the UEIP and ECP source replacement and SChE source installation visits in 2004, detailed dose rate measurements were performed and the measurement results were included in the radiation safety reports. The radiation safety reports indicate that during and after source installation and source replacement the individual doses, as well as, the gamma and neutron dose rates around the BDMS did not exceed the Russian radiation safety limits. LLNL provided also assistance in reviewing the translations of the radiation safety reports. The HEU-TIP health physicist proposed and successfully negotiated the application of more relaxed regulatory limits based on lower occupancy requirements for the BDMS dose rates at UEIP and SChE. The relaxed limits will allow the use of stronger sources that can improve the accuracy of the mass flow measurement and can increase the time between source changes resulting in substantial savings to the HEU-TIP.

\section{Relative Cf source measurements}

LLNL assisted in developing procedures for the californium sources relative measurements at the ECP, UEIP and SChE blend point locations and coordinated the procedures with the VNIITF staff. LLNL analyzed the raw data from these measurements and concluded that they are consistent with the data from the old (removed) californium sources, the "reference" californium sources and the source passports data. The relative measurements between the old (removed), "reference", and 
the currently installed californium sources at all plants provide assurance that the BDMS neutron sources are not a cause of any anomalies in the mass flow data. The source measurements data will provide also seamless continuation of quality mass flow data after the californium sources are replaced in two years.

TV monitoring system and neutron detection equipment

LLNL provided support in finding and implementing technical solutions to the presence of U.S. monitors during source change and californium source relative measurements. LLNL assisted in testing the neutron detection system (Rem Cube) that allows a substantial reduction of overall and per source measurement time. LLNL purchased, assembled, tested and developed the technical documentation for the TV monitoring system that allows U.S. monitors and plant personnel to avoid unnecessary exposure while remotely observing source change and relative source measurement operations. Both systems were shipped to VNIITF and were successfully used during source replacement at ECP and UEIP and during BDMS installation at SChE.

\section{BDMS sources specifications}

LLNL provided assistance for developing the Co-57, Cf-252 and Am-241 source specifications for the BDMS sources at UEIP, ECP and SChE. The source specifications were developed in a manner to maximize the output and the reliability of the BDMS measurements, and in the same time to comply with the Russian Federation radiation safety regulatory limits. The specifics of the dose rate measurement instrumentation and treatment of measurement errors were taken into account in the development of the source specifications.

\section{SChE BDMS installation support}

HEU-TIP health physicist successfully negotiated with SChE experts a reduced reasonable funding for the radiation safety equipment purchases for the SChE BDMS. In support of the SChE request for real-time neutron dosimetry LLNL shipped a bubble dosimeter reader together with its documentation and computer. A broad scope of activities, including dose rate measurement methodology, radiation survey instrumentation, radiation safety report, neutron dosimetry, and californium source relative measurements, were discussed with SChE radiation safety staff and agreed upon. Before and after the installation of the BDMS sources the neutron and gamma dose rates were measured cooperatively by the Russian and U.S. radiation safety professionals according to the agreed methodology. Based on a U.S. draft report, a radiation safety report was produced in cooperation with the $\mathrm{SChE}$ radiation safety staff. The report documented the compliance of the BDMS radiological environment with the Russian Federal regulations. The report also states that the individual radiation doses for both the Russian and U.S. personnel were significantly below the established Russian limits, that there was no unjustified personnel exposure during the source handling operations and that all operations were designed and conducted taking into the account the ALARA (As Low As Reasonably Achievable) principle. The U.S. delegation justified and SChE agreed to apply for the BDMS room dose rate limits for rooms not permanently occupied (a.k.a. "relaxed" limit). The radiation safety report with the "relaxed" radiation safety limits was signed by the SChE and U.S. health physicists and was brought back to the 
United States. SChE will include the signed radiation safety report in the documentation packet for the GosAtomNadzor (GAN) certification of the BDMS at SChE.

\section{Bubble dosimeters}

During CY 2004 LLNL shipped 180 bubble dosimeters with high sensitivity ( 20-30 bubbles per mrem) to ECP, UEIP and SChE to support the BDMS neutron sources changes and installation (60 dosimeters per campaign). The bubble dosimeters are used to measure the personal neutron doses for the involved plant, VNIITF and U.S. personnel, as well as, for area monitoring around BDMS. The bubble dosimeter information is valuable for the U.S. monitors and the Russian personnel as an immediate indication in case of a significant exposure or radiation leakage from the BDMS shielding. In 2004 LLNL experienced delays in getting the dosimeters in time due to issues associated with U.S. Embassy Moscow clearance of the shipments. A solution was found in keeping a back-up supply of bubble dosimeters at Pragma in Ekaterinburg. Shipping the bubble dosimeters from Pragma to any of the BDMS sites can be done on a short notice and takes one to two days for the dosimeters to arrive at the final destination. Since the bubble dosimeters have relatively short warranty, the back-up supply at Pragma usually consists of dosimeters delayed from the previous shipment and redirected to Pragma. For example, the delayed bubble dosimeters, intended for the SChE BDMS installation in October 2004, were kept at Pragma and were used for the ECP source change in March 2005.

\section{Information on DARTS}

The BDMS sources and bubble dosimeter information on DARTS was updated and expanded in the last year. The available data on DARTS in the BDMS directory include two folders - BDMS Sources and Bubble Dosimeters for the use of the HEU community. The BDMS Sources folder contains subfolders for:

- All current and past Cf-252, Co-57 an Am-241 passports for UEIP, ECP and SChE BDMS sources

- Co-57, Am-241 and Cf-252 source specifications for current and upcoming source changes/installation

- All radiation safety reports (dose rate) in English and the Russian originals for UEIP, ECP and SChE

- Tables (in Excel spreadsheet format) of the detailed dose rate (gamma+neutron) measurements at UEIP, ECP and SChE

- Tables (in Excel spreadsheet format) of the relative californium source measurements of the new, old, and the reference sources with any pertinent information for source changes and installations at the three plants

- Tables of the Cf-252, Co-57 and Am-241 source positions at UEIP, ECP and SChE

Bubble dosimeters' folder on DARTS contains:

- Test results from Doza (in Russian)

- Bubble dosimeter Accreditation certificate - original in Russian and the English translation

- Accreditation testing report and description - in Russian and in English 


\section{Reporting}

In 2004 LLNL provided the following reports related to the health physics issues of the HEU-TIP activities:

- Post trip dose reports to the DOE's HEU-TIP management after each trip

- Quarterly bioassay (internal dosimetry) reports to the DOE's HEU-TIP management

- 2003 Annual health physics report to the DOE's HEU-TIP management

- 2003 Annual Occupational Dose reports to each monitor that had a trip to Russia

- 2003 Annual Occupational Dose reports to the POC for all monitors in his area

- U.S.-Russian radiation safety reports for regulatory compliance after SChE BDMS installation and UEIP and ECP BDMS source replacement

- BDMS health physics issues were reported as part of the consensus trip reports for the ECP and UEIP source change trips

- Reports on various health physics topics requested by the HEU-TIP management

In 2004, the HEU-TIP activities in Russia were conducted in a radiologically safe manner for the HEU-TIP monitors in accordance with the expectations of the HEU-TIP staff, NNSA and DOE. The HEU-TIP now has nine years of successful experience in developing and providing health and safety support in meeting its technical objectives. 


\section{Appendix A}

\section{Evaluation of the Lower Level of Detection (LLD) for the HEU-TIP TLDs}

To assess the impact of the airport x-ray screening of the luggage the readings of 15 TLDs carried in the carry-on luggage and the readings of 12 TLDs carried in the checked-in luggage were evaluated. The test TLDs were carried to all Russian plants under the HEU Program, however, they were not used for personnel monitoring (i.e. they were not exposed to any radiation but airport x-ray screening and in-flight background radiation). DOE Methodology for calculating the LLD is provided in the DOE Standard for Performance Testing of Personnel Dosimetry Systems DOE/EH-0027. The formula for Low Level of Detection (LLD) is

$$
L L D=2\left(k \sigma_{0}+\text { alter }^{2} H_{B}\right) /\left(1-\text { alter }^{2}\right)
$$

where

$$
\text { alter }=k^{*} \mathrm{~S} /(1+\mathrm{B})
$$

$k=1.75-$ single-sided $95 \%$ confidence level value with $5 \%$ false positive and negative values

$\mathrm{S} \quad=$ standard deviation of readings of DOELAP test TLDs dosimeters

$\mathrm{B} \quad=$ bias of DOELAP test TLD readings

$0 \quad=$ absolute standard deviation of the background dosimeters readings

$\mathrm{Hb} \quad=$ average background dosimeter readings

The bias and standard deviation of DOELAP (DOE Laboratory Accreditation Program) readings were taken from DOELAP tests conducted previously in the lab with preexposed TLDs sent for evaluation by DOELAP. Since the x-ray energy of the airport screening machines is not known and it may vary from airport (or manufacturer) to airport (manufacturer), the bias and the standard deviation were taken for two energies: standard DOELAP x-ray and Cs source energies. The more conservative of the two values was adopted for the LLD.

\section{Calculation of the LLD for checked-in TLDs}

Using the data from the TLDs transported in carry-on luggage in the airport x-ray exposure study yields

LLD for whole body deep dose is evaluated to be 35 mrem

LLD for the shallow (skin) dose is evaluated to be $45 \mathrm{mrem}$

\section{Calculation of the LLD for carry-on TLDs}

Using the data from the TLDs transported in carry-on luggage in the airport x-ray exposure study yields

LLD for whole body deep dose is evaluated to be 20 mrem

LLD for the shallow (skin) dose is evaluated to be $18 \mathrm{mrem}$ 


\section{Appendix B}

\section{Averaged exposures to checked-in luggage (in mrem) from airport x-ray screening}
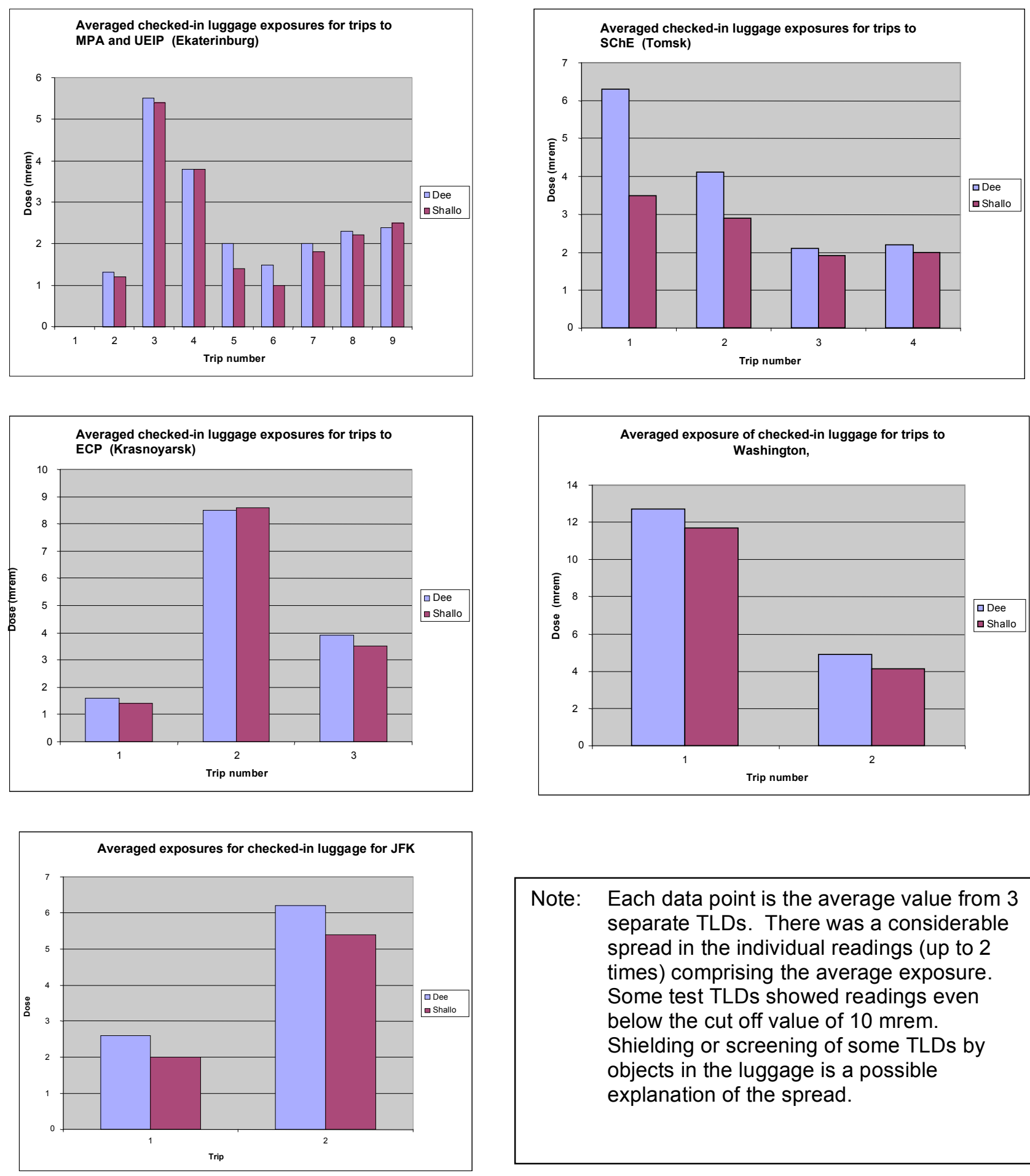

Note: Each data point is the average value from 3 separate TLDs. There was a considerable spread in the individual readings (up to 2 times) comprising the average exposure. Some test TLDs showed readings even below the cut off value of 10 mrem. Shielding or screening of some TLDs by objects in the luggage is a possible explanation of the spread. 


\section{Appendix C}

\section{Minimum Detectable Dose (MDD) from Uranium Bioassays}

The Minimum Detectable Dose (MDD) is the lowest value of committed effective dose equivalent (CEDE, a dose a person will receive for 50 years following a single intake) that would be expected to be reliably detected based on a single bioassay result. The bioassay samples undergo radiochemical preparation followed by state-of-the-art ICP (inductively coupled plasma) mass spectrometry analysis by LLNL bioassay lab. The results are reported as a concentration of uranium by mass in the urine. Several key assumptions are used by the internal dose dosimetrist in the determination of any potential internal dose:

- Average natural background is about 0.01 micrograms of U-238 per liter (based on LLNL and PNNL studies)

- Reference Man excretion rate $=1.4$ liters per day (standard assumption)

- Breathing particle size distribution $=5$ microns AMAD (standard assumption)

- Use of the new ICRP-66 lung model, and the new ICRP-67/68 etc, biokinetic models for uranium (ICRP = International Council on Radiation Protection)

- Different solubility classes are assumed for the main Uranium compounds encountered in the HEU-TIP

- $\mathrm{UF}_{6}$ (uranium hexafluoride) would be very soluble (Type F) material

- Oxides of uranium (e.g., $\mathrm{U}_{3} \mathrm{O}_{8}$ ) are assumed to be moderately soluble (Type M) material

- Metal fumes or powder and high-fired oxides of uranium (perhaps $\mathrm{UO}_{2}$ ) are assumed to be very insoluble (Type $\mathrm{S}$ ) material.

Three of the most critical factors influencing the minimum detectable dose (MMD) are the physical and chemical form (solubility) of U compounds, the time between potential $\mathrm{U}$ intake and providing the bioassay sample, and uranium enrichment with U-235 and U234. Although all $U$ isotopes have approximately the same detection level by mass, their minimum detectable dose differs significantly. Higher enriched uranium compounds have higher MDD since U-235 and especially U-234 have much higher specific activities then U-238. The relationship between MMD and these three factors is provided in the table below and the graphs on the next pages. 


\section{Appendix C (continued)}

\begin{tabular}{|l|c|c|c|c|c|c|c|c|c|}
\hline Material & \multicolumn{3}{|c|}{$\mathbf{U F}_{\mathbf{6}}$} & \multicolumn{3}{c|}{$\mathbf{U}_{\mathbf{3}} \mathbf{O}_{\mathbf{8}}$} & \multicolumn{3}{c|}{ U metal } \\
\hline Solubility & $\mathrm{F}$ & $\mathrm{F}$ & $\mathrm{F}$ & $\mathrm{M}$ & $\mathrm{M}$ & $\mathrm{M}$ & $\mathrm{S}$ & $\mathrm{S}$ & $\mathrm{S}$ \\
\hline $\begin{array}{l}\text { Enrichment } \\
\text { mass \% }\end{array}$ & $\mathbf{D U}$ & $\mathbf{5 \%}$ & $\mathbf{9 0 \%}$ & $\mathbf{D U}$ & $\mathbf{5 \%}$ & $\mathbf{9 0 \%}$ & $\mathbf{D U}$ & $\mathbf{5 \%}$ & $\mathbf{9 0 \%}$ \\
\hline $\begin{array}{l}\text { Days after } \\
\text { intake }\end{array}$ & $\begin{array}{l}\text { MDD } \\
\text { (rem) }\end{array}$ & $\begin{array}{l}\text { MDD } \\
\text { (rem) }\end{array}$ & $\begin{array}{l}\text { MDD } \\
\text { (rem) }\end{array}$ & $\begin{array}{l}\text { MDD } \\
\text { (rem) }\end{array}$ & $\begin{array}{l}\text { MDD } \\
\text { (rem) }\end{array}$ & $\begin{array}{l}\text { MDD } \\
(\mathbf{r e m})\end{array}$ & $\begin{array}{l}\text { MDD } \\
\text { (rem) }\end{array}$ & $\begin{array}{l}\text { MDD } \\
\text { (rem) }\end{array}$ & $\begin{array}{l}\text { MDD } \\
\text { (rem) }\end{array}$ \\
\hline $\mathbf{3}$ & $1.49 \mathrm{E}-5$ & $1.09 \mathrm{E}-4$ & $3.04 \mathrm{E}-2$ & $2.21 \mathrm{E}-4$ & $1.75 \mathrm{E}-3$ & $4.92 \mathrm{E}-1$ & $2.42 \mathrm{E}-2$ & $1.81 \mathrm{E}-1$ & $5.71 \mathrm{E}+1$ \\
\hline 7 & $2.19 \mathrm{E}-5$ & $1.61 \mathrm{E}-4$ & $4.47 \mathrm{E}-2$ & $2.92 \mathrm{E}-4$ & $2.31 \mathrm{E}-3$ & $6.50 \mathrm{E}-1$ & $3.28 \mathrm{E}-2$ & $2.50 \mathrm{E}-1$ & $7.01 \mathrm{E}+1$ \\
\hline 10 & $2.85 \mathrm{E}-5$ & $2.09 \mathrm{E}-4$ & $5.81 \mathrm{E}-2$ & $3.47 \mathrm{E}-4$ & $2.74 \mathrm{E}-3$ & $7.72 \mathrm{E}-1$ & $3.92 \mathrm{E}-2$ & $3.00 \mathrm{E}-1$ & $8.39 \mathrm{E}+1$ \\
\hline 20 & $6.11 \mathrm{E}-5$ & $4.49 \mathrm{E}-4$ & $1.25 \mathrm{E}-1$ & $5.35 \mathrm{E}-4$ & $4.23 \mathrm{E}-3$ & $1.19 \mathrm{E}+0$ & $6.15 \mathrm{E}-2$ & $4.70 \mathrm{E}-1$ & $1.31 \mathrm{E}+2$ \\
\hline 30 & $1.12 \mathrm{E}-4$ & $8.25 \mathrm{E}-4$ & $2.29 \mathrm{E}-1$ & $7.10 \mathrm{E}-4$ & $5.62 \mathrm{E}-3$ & $1.58 \mathrm{E}+0$ & $8.15 \mathrm{E}-2$ & $6.22 \mathrm{E}-1$ & $1.74 \mathrm{E}+2$ \\
\hline
\end{tabular}

Note that MDDs in the table do not consider any chemical toxicity - only the 50-year committed effective dose equivalent (CEDE) received from inhalation.

One can see that urine bioassay alone is generally quite adequate for depleted $U$ and natural U. Dose monitoring sensitivity decreases rapidly as the enrichment increases, and as the solubility goes from Type F to Type S. Dose sensitivity for highly enriched, highly insoluble uranium is very poor. In these cases the bioassay results are supplemented with workplace radiological monitoring data such as airborne uranium concentration and surface contamination. The relationship between MMD and U solubility and time after a potential intake (inhalation) is provided in graphical form for HEU (90\% enrichment) and LEU (5\% enrichment) on the next pages. 
Appendix C (continued)

Minimum Detectable Dose (CEDE) - 5\% LEU

Using ICP-MS Spot Urine Sampling for U-238

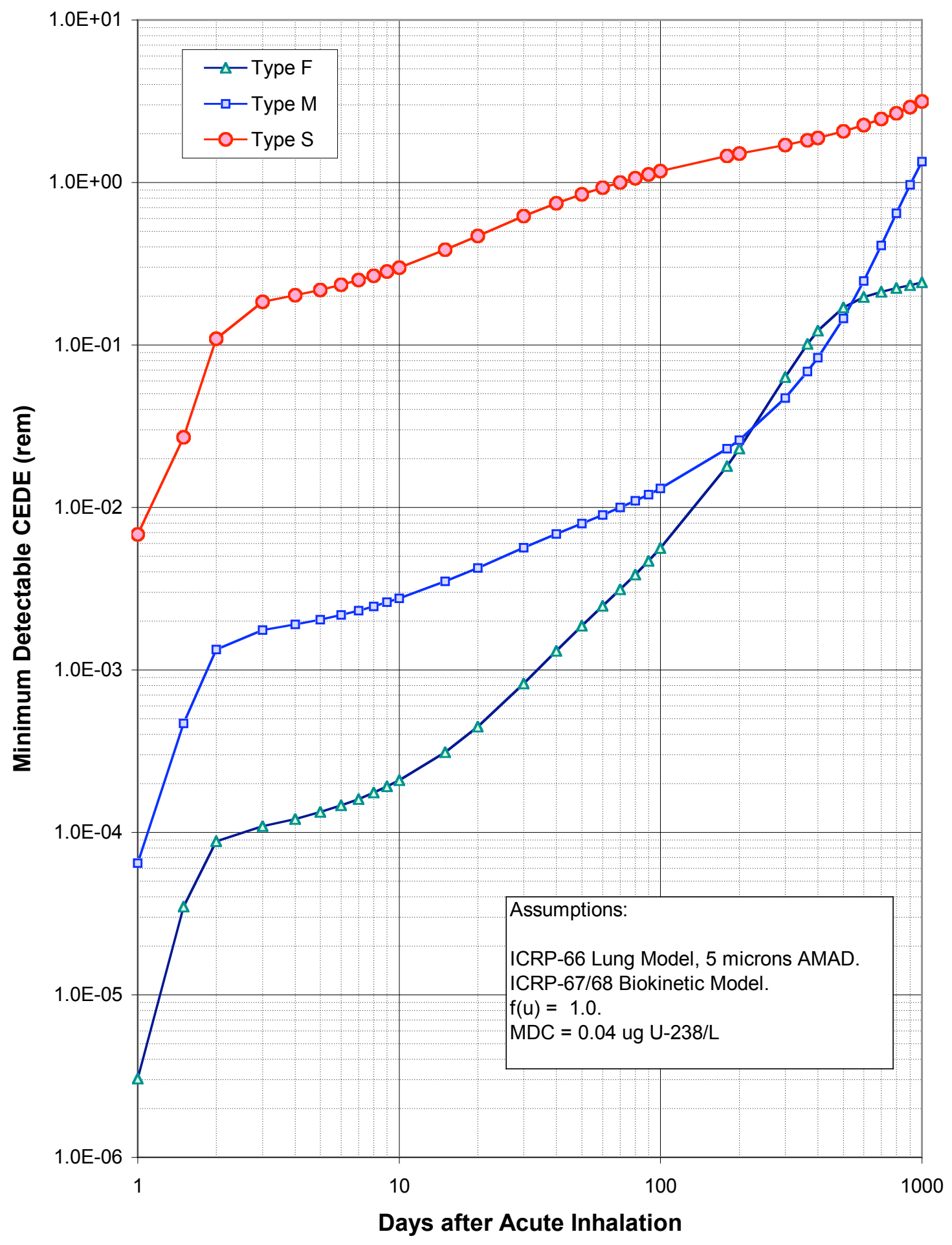


Appendix C (continued)

Minimum Detectable Dose (CEDE) - 90\% HEU

Using ICP-MS Spot Urine Sampling for U-238

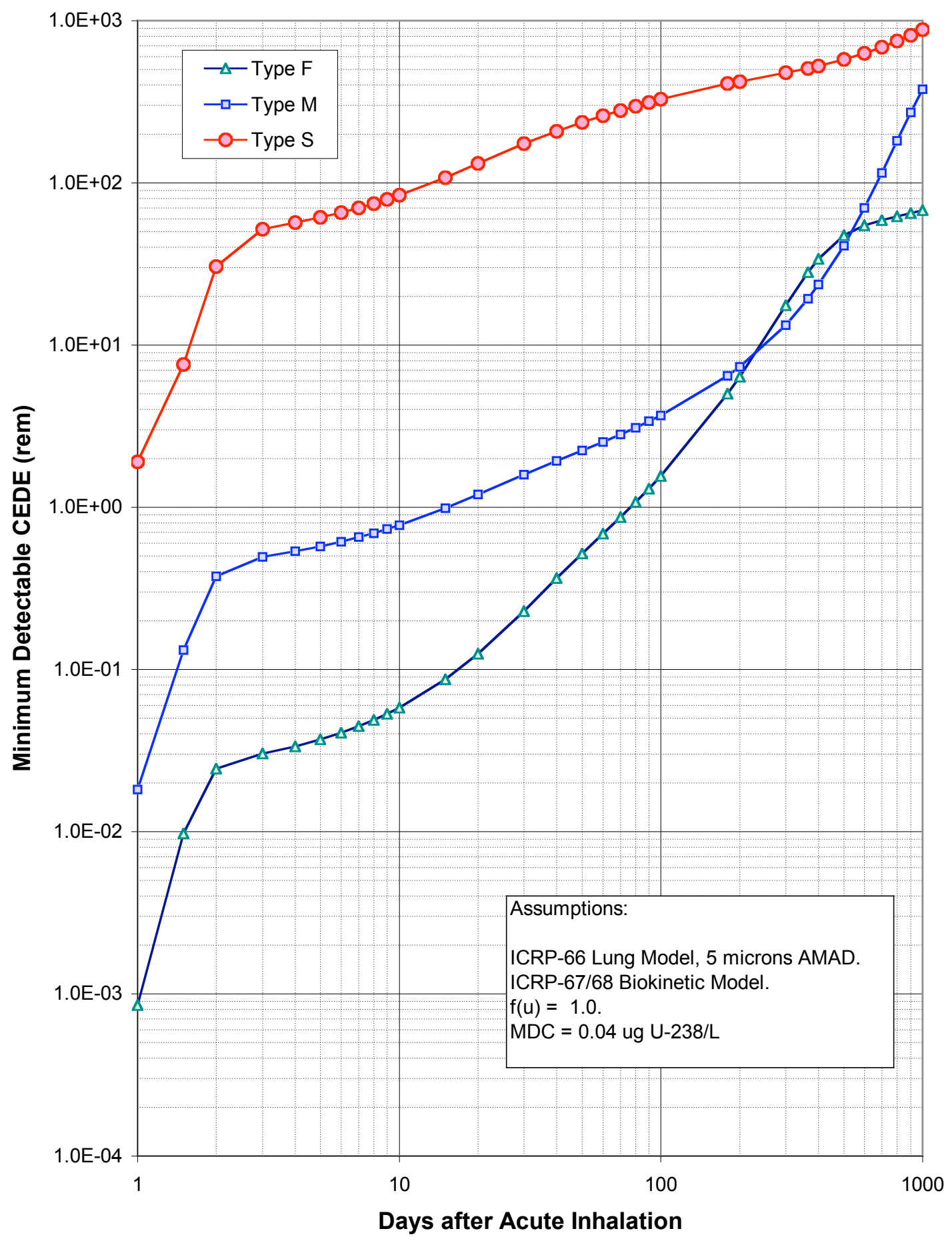




\section{Appendix D}

\section{Timely Bioassay Sample Compliance}

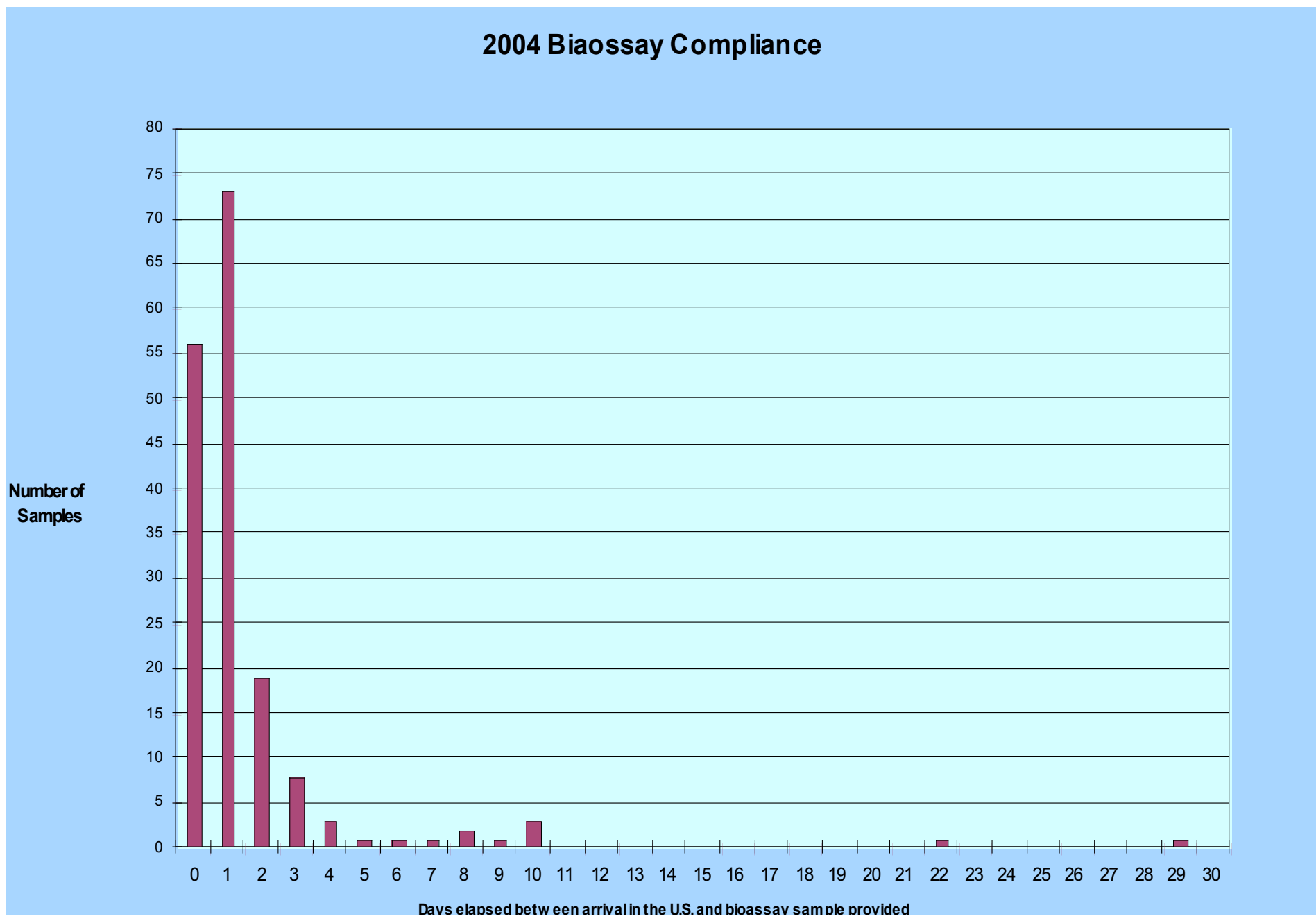




\section{Appendix E}

Appendix $\mathrm{E}$ is a separate document that is marked C/FIG-MOD 